\title{
Peritonitis Following Endoscopic Polypectomy in a Peritoneal Dialysis Patient: The Need for Antibiotic Prophylaxis
}

Colonoscopy performed by an experienced endoscopist is a remarkably safe procedure. The incidence of perforation of the colon as a result of colonoscopy has been estimated to be between $0.1-0.8 \%$ for diagnostic examinations and $0.5-3 \%$ for therapeutic procedures [1]. We report a patient, treated with peritoneal dialysis because of end-stage renal failure, who developed peritonitis following intestinal endoscopy and polypectomy. Peritonitis is a major complication in patients treated with Continuous Ambulatory Peritoneal Dialysis (CAPD) [2]. It is caused mainly by bacteria from skin flora, entering the peritoneal cavity intraluminally or extraluminally via the catheter tunnel. In addition, intestinal perforation due to diverticulitis can cause severe peritonitis, necessitating laparotomy and removal of the catheter. In the last few years several cases of endoscopy induced peritonitis in CAPD patients have been reported [3-7]. The pathophysiological mechanisms involved are discussed. We recommend prophylactic treatment with antibiotics for CAPD patients undergoing intestinal endoscopy and polypectomy.

A 51-year-old female patient had been maintained on Continuous Cyclic Peritoneal Dialysis, another modality of peritoneal dialysis, since 1990. In 1982 the patient started on chronic intermittent hemodialysis because of end stage renal disease secondary to nephrolithiasis and recurrent pyelonephritis. She underwent kidney transplantation three times. In May 1992 she developed symptomatic anemia due to fecal blood loss. A colonoscopy was performed with an Olympus type Q20 after polyethylene glycol purgation. In the sigmoid both a sessile and a pedunculated polyp with dimeters of 3-4 mm were removed with the hot biopsy forceps. Histologic examination revealed hyperplastic polyps. Within $12 \mathrm{~h}$ after the procedure the patient developed $\mathrm{ab}$ dominal pains, fever and a cloudy dialysate outflow. The abdomen was diffusely tender with rebound tenderness, but without abdominal muscle rigidity. Radiographic examination did not demonstrate free air in the abdomen. Dialysate cell counts showed an increased number of leukocytes $\left(2.0 \times 10^{9} / 1\right)$ with $89 \%$ polymorphonuclears (PMNs) at differential counting. A Gram stain of the fluid showed gram-negative rods. The patient was treated with intraperitoneal cefuroxime and tobramycin. The dialysate leukocyte count returned to normal $\left(<0.1 \times 10^{9} / 1\right)$ within 3 days. After 5 days of treatment the leukocytes in the peritoneal fluid rose again to $3.7 \times 10^{9}$ cells/l on day 6 and to $24.8 \times$ $10^{9}$ cells/l on day 7 with more than $80 \%$ PMNs at differential counting, with a concomitant increase in abdominal symptoms. Culture results of the peritoneal dialysate taken on the first day after colonoscopy showed three types of anaerobes (Peptostreptococcus asaccharolyticus, Bacteroides disiens and Bacteroides ureolyticus). On day 6 after colonoscopy Bacteroides disiens was cultured again from the dialysate. The antibiotics were changed to cefuroxime and metronidazole, administered intraperitoneally and intravenously respectively. Within 7 days the dialysate leukocyte counts returned to normal again and abdominal symptoms gradually disappeared. The antibiotic treatment was given for a period of 17 days.

In view of the number of cases reported (Table 1) peritoneal dialysis patients would seem to have an increased risk of developing peritoneal infections following lower-intestinal endoscopy [3-7]. There is a number of potential reasons for this increased risk.
Table 1: Peritonitis following colonoscopy in peritoneal dialysis patients.

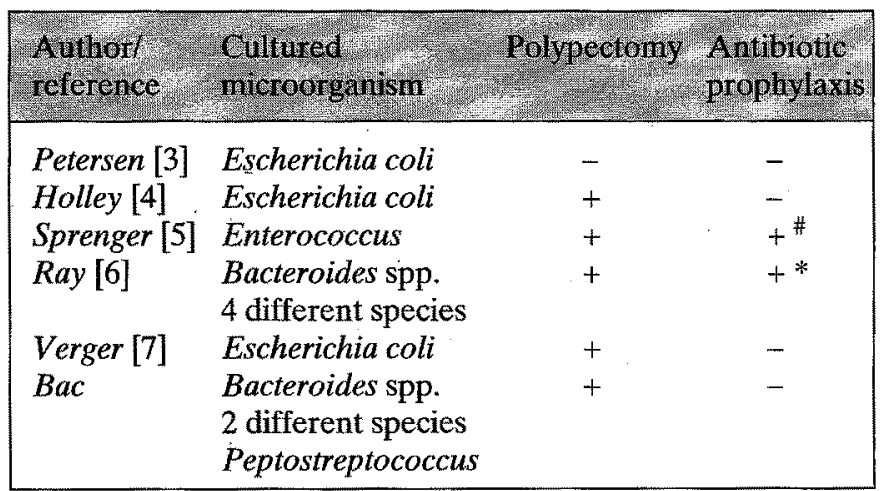

\# Vancomycin and gentamycin were given intravenously; * cephalothin was given intraperitoneally.

First, the continuous exchange of dialysate in the peritoneal cavity results in dilution of both cellular and humoral components of the host defense system, such as opsonins [8]. Secondly, the unphysiological composition of peritoneal dialysate, including low $\mathrm{pH}$ and high glucose content, may impair the function of phagocytic cells, thereby increasing the risk of infection $[9,10]$. The presence of a foreign body (the peritoneal catheter) may also increase the risk of developing and maintaining peritoneal infections.

Theoretically, there are two different routes for bacteria to enter the peritoneal cavity during endoscopy. First, translocation of bacteria to mesenteric lymph nodes and the portal circulation may result in systemic bacteremia with subsequent peritoneal seeding, resulting in peritonitis. It has been shown that gram-negative aerobic enteric bacteria translocate more efficiently from the gastro-intestinal tract than other bacteria, especially obligate anaerobes $[11,12]$. It could be possible that colonoscopy predisposes to bacterial translocation and subsequent hematogenic peritonitis.

On the other hand colonoscopy itself can result in serosal tears and asymptomatic microperforations resulting in transmural migration of the gut flora [1]. It is remarkable that in five of the six reported cases peritonitis occurred after polypectomy (Table 1). This procedure causes a local mucosal defect through which, under high pressure caused by the endoscope, intestinal flora can easily gain access to all layers of the colonic wall and pass through the serosa into the peritoneal cavity. In patients on CAPD, peritonitis could develop more easily due to the absence of local bactericidal and opsonic activity. In these cases, polymicrobial infections predominantly caused by anaerobic bacteria, as described in this case report, may be expected.

Received: 13 December 1993/Accepted: 11 April 1994

D. J. Bac, M. D., M. van Blankenstein, Gastroenterology Section; S. de Marie, , Dept. of Bacteriology; M. W. J. A. Fieren, Nephrology Section; Dept. of Internal Medicine, University Hospital Rotterdam-Dijkzigt, Dr. Molewaterplein 40, NL-3015 GD Rotterdam, The Netherlands. 
Preventative antibiotic therapy in patients maintained on peritoneal dialysis undergoing colonoscopy should be prescribed when polypectomy is anticipated. This prophylaxis should cover anaerobic as well as gram-positive and gram-negative enteric aerobic organisms. In view of the pathophysiological mechanisms dis-

\section{References}

1. Kavin, H., Sinicrope, F., Esker, A. H.: Management of perforation of the colon at colonoscopy. Am. J. Gastroenterol. 87 (1992) 161-167.

2. Nolph, K. D., Lindblad, A. S., Nowak, J. W.: Continuous ambulatory peritoneal dialysis. N. Engl. J. Med. 318 (1988) 1595-1599.

3. Petersen, J. H., Weesmer, R. E., Giannella R. A.: Escherichia coli peritonitis after left-sided colonoscopy in a patient on continuous ambulatory peritoneal dialysis. Am. J. Gastroenterol. 82 (1987) 171-172.

4. Holley, J., Seibert, D., Moss, A.: Peritonitis following colonoscopy and polypectomy: a need for prophylaxis? Perit. Dial. Bull. 7 (1987) 105-106.

5. Sprenger, R., Neyer, U.: Enterococcus-peritonitis after endoscopic polypectomy: need for prophylactic antibiotics. Perit. Dial. Bull. 7 (1987) 263.

6. Ray, S. M., Piraino, B., Holley, J.: Peritonitis following colonoscopy in a peritoneal dialysis patient. Perit. Dial. Int. 10 (1990) 97-98.

7. Verger, C., Danne, O., Vuillemin, F.: Colonoscopy and continuous ambulatory dialysis. Gastrointest. Endosc. 33 (1987) 334-335. cussed above, one might consider draining the peritoneal cavity prior to intestinal endoscopy and leaving it empty for some time after the procedure.

D. J. Bac, M. van Blankenstein, S. de Marie, M. W. J. A. Fieren
8. Keane, W. F., Comty, C. M., Verbrugh, H. A., Peterson, P. K.: Opsonic deficiency of peritoneal dialysis effluent in continuous ambulatory peritoneal dialysis. Kidney Int. 25 (1984) 539-543.

9. Van Bronswijk, H., Verburgh, H. A., Heezius, H. C. L. M.: Dialysis fluids and local host resistance in patients on continuous ambulatory peritoneal dialysis. Eur. J. Clin. Microbiol. Infect. Dis. 7 (1988) 368-372.

10. Duwe, A. K., Vas, S. I., Weatherhead, J. W.: Effects of the composition of peritoneal dialysis fluid on chemiluminescence, phagocytosis, and bactericidal activity in vitro. Infect. Immun. 33 (1981) 130-135.

11. Runyon, B. A.: Pathogenesis and diagnosis of spontaneous bacterial peritonitis. In: $J$. Rodes, $V$. Arroyo (eds.): Therapy in liver disease. Ediciones Doyma, Barcelona 1991, pp. 388-396.

12. Steffen, E. K., Berg, R. D., Deitch, E. A.: Comparison of translocation rates of various indigenous bacteria from the gastrointestinal tract to the mesenteric lymph node. J. Infect. Dis. 157 (1988) 1032-1038.

\section{Meetings}

\section{4-18 August 1994}

\section{Progress in Clinical Virology}

Stockholm, Sweden. Contact: Meetings Secretariat, Stockholm Convention Bureau, Box 6911, S-102 39 Stockholm, Sweden.

\section{5-27 August 1994}

\section{5th International Symposium on New Quinolones}

Singapore. Contact: The Symposium Secretariat, 336 Smith St., 06-302 New Bridge Centre, Singapore 0105.

\section{4-8 September 1994}

\section{Conference of the Hospital Infection Society}

London, UK. Contact: Conference Associates and Services, Ltd., Congress House, 55 New Cavendish St., London, WIM7RE, UK.

\section{4-7 October 1994}

34th Interscience Conference on Antimicrobial Agents and Chemotherapy

Orlando, FL, USA. Contact: Meetings Department. Amer- ican Society for Microbiology, 1325 Massachusetts Ave. NW, Washington, DC 20005-4171, USA.

\section{4-7 December 1994 \\ 4th Western Pacific Congress of Chemotherapy and Infectious Diseases}

Manila, Philippines. Contact: Tropical Disease Foundation, Manahan Annex, Makati Medical Centre, 2 Amorsolo St., Legaspi Village, Makati, Manila, Philippines.

\section{6-9 December 1994 \\ Second International Congress on the Management of In- fection \\ Amsterdam, The Netherlands. Contact: Mr. James Arthur, Gardiner-Caldwell Communications Ltd., The Old Ribbon Mill, Pitt Street, Macclesfield, Cheshire SK11 7PT, UK.}

